\title{
EL CUENTO ULTRACORTO BAJO EL MICROSCOPIO
}

\author{
LAURO ZAVALA \\ Universidad Autónoma Metropolitana
}

La brevedad en la escritura siempre ha ejercido un gran poder de seducción. Entre las formas de escritura radicalmente breve con valor literario podrían mencionarse el haiku, el epigrama y la poesía fractal.

En lo que sigue propongo un modelo para el estudio de los cuentos cuya extensión es menor a la convencional, así como algunos ejemplos de su presencia en la literatura mexicana contemporánea. Aquí llamaré cuento breve a esta clase de narrativa literaria.

En la segunda parte de estas notas dirijo mi atención a la existencia de una gran diversidad de formas de hibridación genérica, gracias a la cual el cuento brevísimo se entremezcla, y en ocasiones se confunde, con formas de la escritura como la crónica, el ensayo, el poema en prosa y la viñeta, y con varios géneros extraliterarios.

\section{DEL CUENTO CONVENCIONAL AL ULTRACORTO}

El interés que ha resurgido en los últimos años por el cuento en general, y por el cuento breve en particular, se observa en la reciente publicación de numerosas antologías en diversas lenguas y tradiciones literarias. Para reconocer la vitalidad que tiene el cuento me acogeré aquí al ejemplo de México, observando la historia editorial de algunos libros que contienen cuentos de extensión convencional y cuentos breves.

Debido a su proximidad genérica con otras formas de la escritura, al tratar de ofrecer una definición del cuento breve nos enfrentamos a varios problemas simultáneos: un problema genérico (¿son cuentos?), un problema estético (¿son literatura?), un problema de extensión (¿qué tan breve puede ser un cuento muy breve?), un problema nominal (¿cómo llamarlos?), un problema tipológico (¿cuántos tipos de cuentos muy breves existen?) y un problema de naturaleza textual (¿por qué son tan breves?).

Rlit, LXIV, 128 (2002), 539-553 
Empezaré por responder a la pregunta: ¿cuántos tipos de cuentos breves existen?, pues ésta es la pregunta fundamental y es la que permite responder las demás preguntas. Para estudiar el cuento breve podemos partir del acuerdo que existe entre escritores y críticos al señalar que la extensión de un cuento convencional oscila entre las 2.000 y las 10.000 palabras. Al estudiar las antologías y las investigaciones que se han realizado hasta ahora sobre cuentos cuya extensión es menor a las 2.000 palabras, en lo que sigue propongo reconocer la existencia de tres tipos de cuentos breves. Las diferencias genéricas que existen entre cada uno de estos tipos de cuentos dependen de la extensión respectiva. Aquí propongo llamar a cada uno de estos tipos de relatos, respectivamente, cuento corto, muy corto y ultracorto. Por debajo del límite de las 2.000 palabras parece haber tres tipos de cuento distintos entre sí: cortos (de 1.000 a 2.000 palabras), muy cortos (de 200 a 1.000 palabras) y ultracortos (de 1 a 200 palabras).

\section{LA ESTÉTICA DEL CUENTO CORTO (1.000 a 2.000 palabras)}

Estos cuentos han sido reunidos en diversas antologías de carácter internacional bajo el nombre de sudden fiction o ficción súbita ${ }^{1}$ y también han sido llamados cuentos microcósmicos (en el caso de la ciencia ficción) ${ }^{2}$ o simplemente short shorts (cortos cortos).

Para Irving Howe, quien es autor, coleccionista y estudioso de esta clase de cuentos breves, «en estas obras maestras de la miniatura, la circunstancia eclipsa al personaje, el destino se impone sobre la individualidad, y una situación extrema sirve como emblema de lo universal (...) produciendo una fuerte impresión de estar fuera del tiempo» ${ }^{3}$.

A partir de estas observaciones, el mismo investigador propone una tipología de los cuentos cortos. Un cuento corto puede narrar un incidente o condensar una vida, o bien puede adoptar un tono lírico o alegórico. Las posibilidades señaladas por Howe son las siguientes:

i) Un incidente repentino, lo cual produce epifanías surgidas en un periodo extremadamente corto en la vida de un personaje. Estas epifanías suelen estar despojadas de sus respectivos contextos, condición que obliga

\footnotetext{
1 Robert SHAPARD \& James THOMAS, eds., «Pospalabras» en Ficción súbita. Narraciones ultracortas norteamericanas. Barcelona, Anagrama, 1989 (1986), 239-273. Traducción de Jesús Pardo.

${ }^{2}$ Isaac Asimov; Martin GreEnberg, Joseph D. Olander, eds., Microcosmic Tales. 100 Wondrous Science Fiction Short-Short Stories. New York, Bantam, 1980, 330 p.

${ }^{3}$ Irving Howe, «Introduction» en Short Shorts. An Anthology of the Shortest Stories. Irving Howe \& Ileana Wiener Howe, eds. New York, Bantam Books, 1983, ix-xiv (esp. p. $x)$.
} 
al lector a proyectar sobre la situación un contexto imaginado por él mismo. A partir de esta propuesta de Howe, en el contexto hispanoamericano se podría pensar en textos como «El ramo azul» de Octavio Paz o «El eclipse» de Augusto Monterroso ${ }^{4}$.

ii) Condensación de toda una vida, lograda gracias a la capacidad de comprimirla en una imagen paradigmática. En el contexto norteamericano se podría pensar en «Paper Pills», «The Untold Lie» y otros cuentos breves de la serie escrita por Sherwood Anderson en Winesburg, Ohio ${ }^{5}$.

iii) Imagen instantánea en la que no hay epifanía, tan sólo un monólogo interior o un flujo de memoria. Por ejemplo, «Amargura para tres sonámbulos» de Gabriel García Márquez ${ }^{6}$.

iv) Estructura alegórica, cuya belleza superficial nos puede llevar a resistirnos al placer de su interpretación. Por ejemplo, en la tradición norteamericana, «Un lugar limpio y bien iluminado» de Ernest Hemingway y, en la tradición europea, «Chacales y árabes» de Franz Kafka?.

Al reflexionar sobre esta clase de cuentos, Charles Baxter observa que mientras en las novelas encontramos individuos en el largo y complejo proceso de madurar importantes decisiones morales, en los cuentos de extensión convencional asistimos al momento de la decisión (o a la ilusión de poder tomar una decisión). En ambos casos participamos en algún tipo de acción moral. En cambio en el cuento corto, dice Baxter, lo que observamos es la reacción de un personaje o de una comunidad ante un momento de tensión súbita. En este caso, concluye, no hay (o no parece haber) posibilidad de tomar ninguna decisión. De hecho, esta posibilidad es sustituida por algún tipo de ritual, que se ubica a medio camino entre lo personal y lo colectivo $^{8}$.

Al leer cuentos breves que no pertenecen a la tradición occidental (parábolas budistas, jasídicas o derviches) o que están cercanos al poema en

\footnotetext{
${ }^{4}$ Octavio PAZ, «El ramo azul» en ¿Águila o sol? México, Fondo de Cultura Económica, 1973 (1951), 33-37; Augusto MONTERROSO, «El eclipse» en Obras completas (y otros cuentos). México, Imprenta Universitaria, UNAM, 1959, 47-50.

${ }^{5}$ Sherwood ANDERSON, «Bolitas de papel»; « La mentira no contada» en Winesburg, Ohio. El libro de los grotescos. Barcelona, Editorial Fontamara, 1981 (1919). Traducción del inglés de Emilio Olcina Aya. (Edición crítica: Winesburg, Ohio. Text and Criticism. Edited by John H. Ferres. London, Penguin Books, 1977).

${ }^{6}$ Gabriel GARCÍA MÁRQUEZ, «Amargura para tres sonámbulos» (1949) en Ojos de perro azul, incluido en Todos los cuentos. Bogotá, Editorial Oveja Negra, 1987, 34-37.

7 Ernest HEMINGWAY, «Un lugar limpio y bien iluminado» en Cuarenta y nueve cuentos. Barcelona, Seix Barral, 1987 (1969). Traducción de Carlos Pujol, Mary Rove y N.N., 243-246; Franz KAFKA, «Chacales y árabes» (1917) en Bestiario. Barcelona, Editorial Anagrama, Panorama de Narrativas, núm. 190, 1990, 29-33.

${ }^{8}$ Charles BAXTER, «Introduction» en Sudden Fiction International. 60 Short Short Stories. Robert Shapard \& James Thomas, eds. New York, W.W.Norton, 1989, 17-25 (esp. 21).
} 
prosa (como el cuento lírico) y a diversos géneros extraliterarios, algunas de las características mencionadas desaparecen, y en su lugar encontramos rastros formales propios del género hibridizado o parodiado. $\mathrm{Al}$ ser el cuento breve un género proteico, es riesgoso reducir su diversidad a normas estables.

Entre los cuentos cortos más conocidos encontramos la colección de Pequeños cuentos misóginos (1975) de Patricia Highsmith ${ }^{9}$, la abundante producción cuentística de Mario Benedetti ${ }^{10} \mathrm{o}$ las difícilmente clasificables narraciones breves de Felisberto Hernández, Oliverio Girondo y Macedonio Fernández ${ }^{11}$.

En México encontramos, entre los libros de reciente publicación y que podrían poner en duda cualquier clasificación genérica tradicional los textos de Tiempo transcurrido de Juan Villoro, La lenta furia de Fabio Morábito y Lugares en el abismo de Agustín Monsreal ${ }^{12}$.

\section{LA ESTÉTICA DE CUENTOS MUY CORTOS (200 a 1.000 palabras)}

Esta categoría está constituida por los textos reunidos bajo el nombre de flash fiction $^{13}$, las compilaciones de microhistorias y las narraciones instantáneas y urgentes escritas por mujeres.

Dice Irene Zahava sobre los cuentos muy cortos: son las historias que alguien puede relatar en lo que sorbe apresuradamente una taza de café, en lo que dura una moneda en una caseta telefónica, o en el espacio que alguien tiene al escribir una tarjeta postal desde un lugar remoto y con muchas cosas por contar ${ }^{14}$.

En su teoría sobre el impresionismo y la forma en el cuento, Suzanne C. Ferguson señala que en la estructura clásica decimonónica se puede romper la linealidad de la secuencia narrativa, utilizando estrategias que generan, respectivamente, dos clases de cuentos: elípticos (cuando se omi-

${ }^{9}$ Patricia HighSmITH, Pequeños cuentos misóginos. Madrid, Alfaguara, 1990 (1975). Traducción de Maribel de Juan.

10 Mario BenedetTi, Cuentos completos. México, Alfaguara, 1996, p. 615.

"Felisberto HERnÁndEZ, Obras completas, 3 vols., México, Siglo XXI Editores, 1983; Oliverio GIRONDO, Obra completa. Edición crítica. Madrid / París, Archivos, 1999; Macedonio FERNÁNDEZ, Relato. Cuentos, poemas y misceláneas. Obras Completas, vol. 7. Buenos Aires, Ediciones Corregidor, 1987.

12 Juan Villoro, Tiempo transcurrido. México, Fondo de Cultura Económica, 1986; Fabio MORÁBITO, La lenta furia. México, Vuelta, 1989; Agustín MONSREAL, Lugares en el abismo. México, GV Editores, 1993.

13 James THOMAS, «Introduction» en Flash Fiction. 72 Very Short Stories. James Thomas, Denise Thomas \& Tom Hazuka, eds. New York, W. W. Norton, 1992, 11-14.

${ }^{14}$ Irene ZAHAVA, ed., «Preface» en Word of Mouth. 150 Short-Short Stories by 90 Women Writers. Freedom, California, The Crossing Press, 1990 (esp. p. vii). 
ten fragmentos del relato) o metafóricos (cuando algunos fragmentos del relato no son omitidos, sino sustituidos por elementos disonantes e inesperados) $)^{15}$.

El primer tipo (historias elípticas) corresponde a las primeras dos categorías señaladas anteriormente para el cuento corto (incidente repentino o condensación de una vida, es decir, en ambos casos, intensificación del tiempo). El segundo caso (historias metafóricas) corresponde al monólogo interior o la estructura alegórica. En todas las formas del cuento muy corto se condensan las estrategias que hemos visto utilizadas en el cuento corto.

Los títulos de los cuentos muy cortos suelen ser enigmáticos, y en ellos puede haber ambigüedad temática y formal, hasta el grado de alterar las marcas de puntuación. Los finales suelen ser también enigmáticos o abruptos ${ }^{16}$. Pero siempre se requiere que el lector participe activamente para completar la historia.

En este grupo de cuentos se encuentran «El silencio de las sirenas» incluido en el Bestiario (c. 1924) de Franz Kafka, y libros como la Centuria (Cien breves novelas-río) (1979) de Giorgio Manganelli, el Manual de zoología fantástica (1957) de Jorge Luis Borges, las Historias de cronopios y de famas (1962) de Julio Cortázar y Rajapalabra (1993) de Luis Britto García ${ }^{17}$.

En México encontramos esta clase de narraciones en la sección Arenas Movedizas del libro ¿Aguila o sol? (1949) de Octavio Paz, la Enciclopedia de latinoamericana omnisciencia (1977) de Federico Arana, Gente de la ciudad (1986) de Guillermo Samperio, Castillos en la letra (1986) de Lazlo Moussong (1986), Las vocales malditas (1988) de Oscar de la Borbolla, Amores enormes (1991) de Pedro Angel Palou, La Musa y el garabato (1992) de Felipe Garrido, Léérere (1992) de Dante Medina, los Cuadernos patafísicos (1992) de Hugo Enrique Sáez y La casa en Mango Street (1994) de Sandra Cisneros, y muchos otros a partir de $1995^{18}$.

15 Suzanne C. FERGUSON, «Defining the Short Story. Impressionism and Form» (1982), en The New Short Story Theories. Edited by Charles E. May, Athens, Ohio University Press, 1994, 219-230 (esp. p. 221).

${ }^{16}$ Andrea BELL, «The cuento breve in modern Latin American literature». Ph.D., Stanford University, 1991, p. 30.

${ }_{17}$ Giorgio MANGANElli, Centuria (Cien breves novelas-río). Barcelona, Editorial Anagrama, 1982 (1979); Jorge Luis Borges, Manual de zoología fantástica. México, Fondo de Cultura Económica, 1957. Serie Breviarios, núm. 125; Julio CORTÁZAR, Historias de cronopios y de famas. Buenos Aires, Ediciones Minotauro, 1962; Luis BRITTO GARCíA, Rajapalabra. México, Dirección de Literatura, UNAM, 1993.

${ }^{18}$ Federico ARANA, Enciclopedia de latinoamericana omnisciencia. México, Joaquín Mortiz, 1977; Guillermo SAMPERIO, Gente de la ciudad. México, Fondo de Cultura Económica, 1986; Lazlo Moussong, Castillos en la letra. Xalapa, Universidad Veracruzana, 1986; Óscar DE LA BORBOlla, Las vocales malditas. México, Edición de autor, 1988; Pedro Ángel Palou, Amores enormes. Gobierno del Estado de Guanajuato, 1991; Felipe 


\section{LA ESTÉTICA DEL CUENTO ULTRACORTO (1 a 200 palabras)}

Estos textos constituyen el conjunto más complejo de materiales de la narrativa literaria. Está formado por los fragmentos narrativos seleccionados por Jorge Luis Borges y Adolfo Bioy Casares en su libro Cuentos breves y extraordinarios (1953), y por Edmundo Valadés en El libro de la imaginación (1976). También a esta categoría pertenecen los minicuentos del concurso creado por la revista El Cuento, los microcuentos de la compilación hecha por Juan Armando Epple en América Latina, los casos de Enrique Anderson Imbert y los llamados textículos de Julio Cortázar (especialmente los incluidos en su Último Round y en La vuelta al día en ochenta mundos).

Esta clase de microficciones tienden a estar más próximas al epigrama que a la narración genuina. El crítico alemán Rüdiger Imhof señala en su estudio sobre las metaficciones mínimas que para su comprensión cabal es necesario desviar la atención de las consideraciones genéricas acerca de lo que es un cuento, y dirigirla hacia el asunto más fundamental, que es la escala, es decir, la extensión de estos textos ${ }^{19}$.

La fuerza de evocación que tienen los minitextos está ligada a su naturaleza propiamente artística, apoyada a su vez en dos elementos esenciales: la ambigüedad semántica y la intertextualidad literaria o extraliteraria.

La naturaleza del hipotexto, es decir, del material que está siendo aludido, parodiado o citado, determina a su vez la naturaleza moderna o posmoderna del cuento ${ }^{20}$. Esto significa que cuando el hipotexto es una regla genérica (por ejemplo, si se parodia el estilo de un instructivo cualquiera, en general) nos encontramos ante un caso de intertextualidad posmoderna, es decir, ante un caso de recuperación de la historia. Por otra parte, cuando lo que se recicla es un texto particular (por ejemplo, el mito de las sirenas o un refrán popular) nos encontramos ante un caso de intertextualidad moderna, es decir, ante un rechazo de la historia. Esta diferencia implica relaciones distintas con la tradición literaria.

GARrido, La Musa y el garabato. México, Fondo de Cultura Económica, 1992; Dante Medina: Léérere. México, UNAM, 1992; Hugo Enrique SÁEZ, Cuadernos patafísicos. México, Universidad Autónoma Metropolitana, 1992; Sandra Cisneros, La casa en Mango Street. México, Alfaguara, 1994.

${ }_{19}$ Rüdiger IMHOF, «Minimal Fiction, or The Question of Scale», en Contemporary Metafiction. A Poetological Study of Metafiction in English since 1939. Heidelberg, Carl Winter Universitätsverlag, 1986, 239-251.

${ }^{20}$ Pavao PAVLICIC, «La intertextualidad moderna y posmoderna» en Criterios, México, UAM Xochimilco, 1993, 165-186. Traducción del croata por Desiderio Navarro: «Así pues, el modernismo trató de poetizarlo todo, hasta los metatextos; el postmodernismo transforma todo en metatexto, hasta la poesía» (177). 
La consecuencia de todo lo anterior es que en los microcuentos la presencia de la epifanía es casi exclusivamente textual (o intertextual), es decir, de naturaleza estructural, pues esta epifanía ya no puede recaer en algún personaje y su respectiva situación específica. Esto es así debido a que en estos textos el concepto mismo de personaje ha desaparecido bajo el peso de la intertextualidad o de la ambigüedad semántica. Como ocurre también en la escritura hipertextual (en ciertos programas de computadora), es el lector quien tiene la opción de construir un sentido que luego es conferido al texto, gracias a la superposición de contextos.

También en estos microtextos la ironía está presente, pero suele ser inestable, es decir, no puede ser determinada por la intención de la voz narrativa. Esto se debe a que la intención narrativa en general (y la intención irónica en particular) es indecidible en estos casos, a falta del suficiente contexto para ser interpretada de manera estable ${ }^{21}$.

Afirma Juan Armando Epple, en la introducción a su antología de microcuentos hispanoamericanos, que este género híbrido y proteico es una «metáfora expresiva de los dilemas que viven las sociedades latinoamericanas en sus niveles sociales, ideológicos y de reformulación estética de sentidos» ${ }^{22}$.

Son cuentos ultracortos cada uno de los Ejercicios de estilo (1947) de Raymond Queneau ${ }^{23}$; las parábolas budistas incluidas en la compilación de José Vicente Anaya, Largueza del cuento chino (1981) —en los que se puede estudiar la tradición más antigua de cuentos ultracortos- ${ }^{24}$; las paradójicas parábolas sufis recopiladas por Idries Shah en Las ocurrencias del increíble Mulá Nasrudin (1976) en la tradición derviche ${ }^{25}$; los textos de la sección Museo en El Hacedor (1960) de Jorge Luis Borges ${ }^{26}$, y las recreaciones narrativas que constituyen la multitudinaria Memoria del fuego (1982-1986) de Eduardo Galeano ${ }^{27}$.

${ }^{21}$ Booth WAYNE, A Rhetoric of Irony. Chicago, The University of Chicago, 1974.

22 Juan Armando EPPLE, «Brevísima relación sobre el mini-cuento» en Brevísima relación. Antología del micro-cuento hispanoamericano. Santiago de Chile, Editorial Mosquito Comunicaciones, 1990, 11-19 (esp. p. 18).

${ }^{23}$ Raymond Queneau, Exercises de style. París, Editions Gallimard, 1947. Hay versión en español: Ejercicios de estilo. Versión y estudio preliminar de Antonio Fernández Ferrer. Madrid, Cátedra, 1987.

${ }^{24}$ José Vicente ANAYA, comp.: «Largueza del cuento corto chino» en Largueza del cuento corto chino. Toluca, Universidad Autónoma del Estado de México. 1981, 7-15.

${ }^{25}$ En el caso de la tradición derviche, destacan la difusión y el estudio de los relatos traducidos y editados por Idries SHAH en Las ocurrencias del increíble Mulá Nasrudín. Barcelona, Paidós Orientalia, 1988 (1968); traducción del inglés de A. H. D. Halka; ilustraciones de Richard WiLliams, y Las hazañas del incomparable Mulá Nasrudín. México, Paidós Orientalia, 1990 (1966). Traducción de Manuel Guerra.

${ }^{26}$ Jorge Luis Borges, El Hacedor. Buenos Aires, Emecé, 1960.

${ }^{27}$ Eduardo Galeano, Memoria del fuego, 3 volúmenes. México, Siglo XXI Editores, 1982-1986. 
En alguna ocasión señaló Edmundo Valadés que fue en 1917 cuando se publicó por primera vez un cuento ultracorto en Latinoamérica ${ }^{28}$. Se trata de «A Circe» de Julio Torri, uno de los más importantes cuentos ultracortos de la tradición literaria mexicana. A partir de ese texto seminal se han producido otros como una respuesta intertextual a aquél: «Circe» de Agustí Bartra, «Aviso» de Salvador Elizondo y algunos más en el resto del continente.

En México se pueden encontrar al menos una docena de libros en los que algún autor ha reunido sus cuentos ultracortos: Varia invención (1955) y La feria (1962) de Juan José Arreola; De fusilamientos y otras narraciones (1964) de Julio Torri; Infundios ejemplares (1969) de Sergio Golwarz; Fantasías en carrusel (1978) y Los oficios perdidos (1983) de René Avilés Fabila; Sólo los sueños y los deseos son inmortales, Palomita (1986) de Edmundo Valadés; La oveja negra y demás fábulas (1969) de Augusto Monterroso; El grafógrafo (1972) de Salvador Elizondo; Cuaderno imaginario (1990) de Guillermo Samperio; las secciones Mínima Expresión y Casos de la Vida Real en La sangre de Medusa y otros cuentos marginales (1990) de José Emilio Pacheco; La señora Rodríguez y otros mundos (1990) de Martha Cerda, y Relámpagos (1995) de Ethel Krauze ${ }^{29}$.

De entre estos títulos únicamente los de Samperio y Krauze están constituidos casi exclusivamente por relatos ultracortos; algunos otros son considerados tradicionalmente como novela (La feria) o como novela con una serie de cuentos breves intercalados (La señora Rodríguez y otros mundos).

Por su parte, el libro de Sergio Golwarz tiene estructura infundibuliforme, es decir, en forma de embudo. Empieza con un cuento muy corto (500 palabras), y cada uno de los 42 cuentos sucesivos es más corto que el anterior, hasta cerrar el libro con el cuento más breve del mundo, que tiene el título de «Dios». El texto de este cuento ultracorto dice, simplemente: «Dios». Este cuento merece ser leído cuidadosamente, en particular en un país mayoritariamente católico como México.

Una lectura literal de este cuento, paradójicamente, puede llevar a reconocer lo que podría ser una de las narraciones más extensas imaginables.

${ }^{28}$ Edmundo VALADÉs, «Ronda por el cuento brevísimo» en Paquete: cuento. (La ficción en México). Alfredo Pavón, ed. Tlaxcala, Universidad Autónoma de Tlaxcala, INBA, ICUAP, 1990, 191-197 (esp. p. 195).

${ }^{29}$ Juan José ARreola, Varia invención. Joaquín Mortiz, 1971 (1949); La feria. Joaquín Mortiz, 1971 (1963); Julio TORRI, De fusilamientos y otras narraciones. Fondo de Cultura Económica, 1964; Sergio GolWARZ, Infundios ejemplares. Fondo de Cultura Económica, 1969; René AvilÉS FABILA, Fantasías en carrusel. Eds. Cultura popular, 1978 y Los oficios perdidos. UNAM, 1983; La oveja negra y demás fábulas. Joaquín Mortiz, 1969; Salvador Elızondo, El grafógrafo. Joaquín Mortiz, 1972; Guillermo SAMPERIO, Cuaderno imaginario. Grijalbo, 1990; las secciones Mínima Expresión y Casos de la Vida Real en La sangre de Medusa y otros cuentos marginales. Era, 1990; La señora Rodríguez y otros mundos. Joaquín Mortiz, 1990. 
De hecho, su interpretación (y el hecho de ser considerado como cuento) está en función directa del capital cultural y de la enciclopedia intertextual que posea cada lector, a la vez que acepta que sobre él se puedan efectuar simultáneamente lo que podríamos llamar una lectura elíptica (resaltando sólo algunos episodios) o una lectura parabólica (de carácter metafórico y con final sorpresivo, necesariamente epifánico).

Sin duda, éste es uno de los cuentos ultracortos con mayor densidad genérica y con mayor gradiente de polisemia en la narrativa contemporánea.

\section{EL CUENTO ULTRACORTO: UNA MIRADA BAJO EL MICROSCOPIO}

Lo que aquí llamo cuento ultracorto, como ya señalé, tiene una extensión que no rebasa las doscientas palạbras.

La investigadora venezolana Violeta Rojo propone llamar minicuento a la narrativa que tiene las siguientes características: a) brevedad extrema; b) economía de lenguaje y juegos de palabras; c) representación de situaciones estereotipadas que exigen la participación del lector, y d) carácter proteico. Esto último puede presentarse en dos modalidades: ya sea la hibridación de la narrativa con otros géneros literarios o extraliterarios, en cuyo caso la dimensión narrativa es la dominante; o bien la hibridación con géneros arcaicos o desaparecidos (fábula, aforismo, alegoría, parábola, proverbios y mitos), con los cuales se establece una relación paródica ${ }^{30}$. El ejemplo paradigmático de minicuento es «El dinosaurio» (1959) de Augusto Monterroso.

Por su parte, Andrea Bell, en su investigación sobre lo que ella llama cuento breve incluye el muy corto y el ultracorto, es decir, hasta un límite de 1.000 palabras.

Retomando lo señalado en el apartado anterior, en el estudio de estos minicuentos es necesario considerar, además de la brevedad extrema, los siguientes elementos característicos:

a) Diversas estrategias de intertextualidad (hibridación genérica, silepsis, alusión, citación y parodia).

b) Diversas clases de metaficción (en el plano narrativo: construcción en abismo, metalepsis, diálogo con el lector) (en el plano lingüístico: juegos de lenguaje como lipogramas, tautogramas o repeticiones lúdicas).

c) Diversas clases de ambigüedad semántica (final sorpresivo o enigmático).

d) Diversas formas de humor (intertextual) y de ironía (necesariamente inestable).

${ }^{30}$ Violeta RoJo, «El minicuento: caracterización discursiva y desarrollo en Venezuela» en Revista Iberoamericana, núms. 166-167, enero-junio 1994, 565-573 (esp. 566-7). 
Todos los estudiosos del cuento ultracorto señalan que el elemento básico y dominante debe ser la naturaleza narrativa del relato. De otra manera, nos encontramos ante lo que algunos autores han llamado un minitexto pero no ante un minicuento; es decir un texto ultracorto, pero no un cuento ultracorto.

Sin embargo, el elemento propiamente literario - tanto en los minitextos como en los minicuentos- es la ambigüedad semántica, producida, fundamentalmente, por la presencia de un final sorpresivo o enigmático, que exige la participación activa del lector para completar el sentido del texto desde su propio contexto de lectura.

La intensidad de la presencia de los elementos estructurales indicados hacen del cuento ultracorto una forma de narrativa mucho más exigente para su lectura que la novela realista o el cuento de extensión convencional.

Antes de 1956, fecha de 'publicación de la Breve historia del cuento mexicano de Luis Leal ${ }^{31}$, entre los principales cultivadores del cuento muy breve en México se encontraban Carlos Díaz Dufoo II, Julio Torri, Alfonso Reyes, Octavio Paz, Mariano Silva y Aceves, Genaro Estrada, Juan José Arreola, Juan Rulfo y algunos otros, cuya tradición continúa hasta hoy. Habría que añadir que de todos estos escritores sólo Paz y Reyes llegaron a practicar directamente la escritura del haiku (T. Hadman, $7 ; 20-21)^{32}$.

La actual popularidad del género se puede deber, tal vez, al crecimiento editorial y al incremento de estudios y talleres dedicados al cuento, a la crisis de la sociedad civil (con la consiguiente multiplicación de voces públicas) y sin duda a la creación del Concurso de Cuento Breve de la revista El Cuento.

\section{CUENTO Y POEMA EN PROSA: INSTRUCCIONES PARA CRUZAR LA FRONTERA}

Como he señalado anteriormente, la consideración fundamental en el estudio de todas las formas de textos breves es el problema de la escala. Sin embargo, un rasgo común a todos estos tipos de textos es su tendencia lúdica hacia la hibridación genérica, especialmente en relación con el poema en prosa, el ensayo, la crónica y la viñeta, y con numerosos géneros no literarios.

Este fenómeno, el de la hibridación genérica, ha sido estudiado por Linda Egan en el contexto de la distinción entre crónica y cuento en la escritura de algunos narradores mexicanos contemporáneos. Señala Linda Egan con agudeza que «del llamado artículo de costumbres, inventado en

${ }^{31}$ Luis LEAL, Breve historia del cuento mexicano. Tlaxcala, Universidad Autónoma de Tlaxcala, 1990 (1956).

32 Ty HADMAN, Breve historia y antología del haikú en la lírica mexicana. México, Editorial Domés, 1987 (esp. p. 7, 20-21) . 
México por Guillermo Prieto, se distinguían (al menos) cuatro géneros: el cuento, la crónica, el ensayo y la nota periodística. Nunca ha sido fácil distinguir entre ellos en México» ${ }^{33}$.

$\mathrm{Si}$ esto ocurre en el cuento de extensión convencional, en el caso del cuento muy breve encontramos, además, una gran proximidad con el poema en prosa y, en algunos casos, una apropiación paródica de las reglas genéricas de la parábola o la fábula, o incluso del aforismo, la definición, el instructivo, la viñeta y muchos otros géneros extraliterarios.

Para algunos autores (Bell, Imhof, Baxter), la diferencia entre el cuento ultracorto y el poema en prosa es sólo una cuestión de grado, e incluso puede depender de la manera de leer el texto. Tal vez por esta razón algunos textos de Julio Torri («De fusilamientos», «La humildad premiada» y «Mujeres»), que en base a todo lo visto hasta aquí pueden ser considerados legítimamente como cuentos ultracortos, han sido incluidos en sendas antologías del ensayo y del poema en prosa.

En la antología del poema en prosa en México de Luis Ignacio Helgue$\mathrm{ra}^{34}$ se incluyen varios de los más breves textos de La oveja negra de Augusto Monterroso, del Bestiario de Juan José Arreola, y de Gente de la ciudad de Guillermo Samperio, es decir, textos que pueden ser considerados como cuentos muy cortos o ultracortos. De cualquier manera, todos estos escritores son conocidos principalmente por su trabajo como cuentistas.

En el cuento breve mexicano hay numerosos casos de textos de naturaleza lírica, es decir (en la definición de Ángeles Ezama), construidos a partir de un «yo» narrativo que contempla el mundo de un modo particular, con orientación pictórica o musical, fragmentación temporal y mayor atención al espacio ${ }^{35}$. Esta escritura es muy evidente, por ejemplo, en una tradición que va de los cuentos poéticos de Carlos Díaz Dufoo II hasta la Caja de herramientas de Fabio Morábito. El libro paradigmático es, sin duda, ¿Aguila o sol? de Octavio Paz.

Tal vez es necesario reconocer, como lo hace Irving Howe, que el cuento es a otras formas de la ficción lo que la lírica es a otras formas de la poesía, o, en palabras de Azorín: «El cuento es a la prosa lo que el soneto al verso» ${ }^{36}$.

${ }^{33}$ Linda EGAN, «El 'descronicamiento' de la realidad (el macho mundo mimético de Ignacio Trejo Fuentes)» en Vivir del cuento. (La ficción en México). Tlaxcala, Universidad Autónoma de Tlaxcala, 1995, 143-170 (esp. p. 157).

${ }^{34}$ Luis Ignacio Helguera, ed., Antología del poema en prosa en México. México, Fondo de Cultura Económica, 1993.

35 Ángeles EZAMA GIL, «El cuento y el poema en prosa: El relato lírico» en El cuento de la prensa y otros cuentos. Aproximación al estudio del relato breve entre 1890 y 1900. Zaragoza, Universidad de Zaragoza, 1992 (esp. p. 62).

36 Azorín, «El arte del cuento», $A B C, 17$ de enero de 1944. Citado en el libro de Ángeles Ezama Gil (vid. supra, n. 35), 62, nota 7. 


\section{CUENTO O VIÑETA: DisTiNCIÓN PRECISA PERO IRRELEVANTE}

En varios libros de cuento escritos en un tono lírico se han incluido brevísimas viñetas, es decir, textos en los que hay la descripción de una situación sin ofrecer el contexto al que pertenece, como es el caso de algunos cuentos ultracortos contenidos en De noche vienes de Elena Poniatowska y Sólo los sueños y los deseos son inmortales, Palomita de Edmundo Valadés ${ }^{37}$.

A su vez, en algunos libros de ficción novelesca se han incorporado textos muy breves, como en el ya mencionado caso de La señora Rodríguez y otros mundos de Martha Cerda y de Terra Nostra de Carlos Fuentes, dos autores cuya narrativa es marcadamente metaficcional.

En algunos otros libros no se establece ninguna distinción tipográfica o estructural entre los textos narrativos y la presencia de viñetas. Éstos son libros propiamente híbridos, como Gente de la ciudad, La rebelión de los enanos calvos, Castillos en la letra y La musa y el garabato. Por último, algunos libros contienen viñetas con una narrativa condensada y elíptica, como es el caso de los Relámpagos de Ethel Krauze ${ }^{38}$.

Todo lo anterior nos lleva a concluir que la distinción entre cuento y viñeta puede ser de interés para algunos críticos, pero no lo es para los escritores, al menos en el momento de organizar sus textos para ofrecerlos a la lectura.

\section{ENSAYO NARRATIVO Y OTRAS FORMAS FRONTERIZAS}

El referente imprescindible del desplazamiento genérico entre cuento breve y ensayo en México es el Manual del distraído (1978) de Alejandro Rossi ${ }^{39}$. A partir de este caso paradigmático tal vez podría hablarse de al menos cinco estrategias de hibridación en el cuento breve contemporáneo en México:

En primer lugar hay distintas formas de ensayos narrativos, como los de carácter patafísico (Hugo Sáez en Cuadernos patafísicos) o de carácter hiperbólico y paródico (Hugo Hiriart en Disertación sobre las telarañas) ${ }^{40}$.

${ }^{37}$ Elena POnIATOwSKa, De noche vienes. México, Era, 1989; Edmundo VAladÉs, Sólo los sueños y los deseos son inmortales, Palomita. México, Diana, 1980.

${ }^{38}$ Ethel KraUZe, Relámpagos. México, CNCA / Instituto Coahuilense de Cultura, 1995.

39 Alejandro Rossi, Manual del distraído. México, Fondo de Cultura Económica, 1987 (1978).

${ }^{40}$ Hugo HIRIART, Disertación sobre las telarañas. México, Fondo de Cultura Económica, 1988 (1980). 
Otro grupo de autores escribe libros de crónicas-ensayo de naturaleza narrativa: Carlos Monsiváis, Armando Ramírez, Ignacio Trejo, Emiliano Pérez Cruz, Hermann Bellinghausen, Guillermo Sheridan, José Joaquín Blanco y un largo etcétera.

También hay un nutrido grupo de textos en los que se proponen otras formas híbridas y paródicas. Entre estas formas, difícilmente repetibles, están las siguientes: relato como ensayo epistolar (Bárbara Jacobs en Escrito en el tiempo); parábolas paródicas (Augusto Monterroso en La oveja negra y demás fábulas); banquete platónico (Moreno-Morábito-Castañón en Macrocefalia); crónicas imaginarias (Juan Villoro en Tiempo transcurrido); metaforización narrativa (Fabio Morábito en Caja de herramientas); ucronías oulipianas (Oscar de la Borbolla en Ucrónicas y Las vocales malditas); adivinanzas como cuentos como poemas en prosa (Manuel Mejía Valera en Adivinanzas); reseñas apócrifas (Ilán Stavans en el Manual del perfecto reseñista); parodias parabólicas (René Avilés Fabila en Fantasías en carrusel y varios otros títulos), y crónicas ficcionalizadas (Cristina Pacheco en Sopita de fideo y varios otros títulos) ${ }^{41}$.

Además de los géneros mencionados hasta aquí (poema en prosa, ensayo, crónica y viñeta), hay numerosos géneros de la escritura breve que son hibridizados o parodiados en la narrativa ultracorta. Entre estas formas de escritura breve podrían ser mencionadas las siguientes: escritura oracular, aforismo, mito, definición, instructivo, fábula, palíndromo, solapa, reseña bibliográfica, parábola, confesión, alegoría y grafito. En México hay al menos un grupo de textos escritos en cada uno de estos géneros híbridos. En todos los casos la tónica dominante suele ser la narrativa o los elementos propios del cuento breve o los señalados anteriormente para el cuento ultracorto.

Por último, algunos autores practican una escritura fronteriza de carácter dialógico, es decir, una narrativa breve escrita desde fuera de la literatura, como es el caso de los cuentos cortos y muy cortos del Subcomandante Marcos y de los textos antropológicos de Roger Bartra. El primero es autor de parábolas civiles con una amplia difusión nacional, escritas en la selva lacandona sobre una computadora portátil, y cuyas raíces pertenecen simultáneamente a la cultura indígena y al canon de la tradición occidental ${ }^{42}$. El segundo ha intercalado una serie de parodias parabólicas en su estudio so-

${ }^{41}$ Cristina PACHECo, Para vivir aquí. Grijalbo, 1983; Sopita de fideo. Océano, 1984; Cuarto de azotea. Gernika / SEP, 1986; La última noche del Tigre. Océano, 1987; Para mirar a lo lejos. Gobierno del Estado de Tabasco, 1989; El corazón de la noche. Eds. El Caballito, 1989; Amores y desamores. Selector, 1996.

${ }^{42}$ Subcomandante Marcos, Cuentos para una soledad desvelada. México, FZLN, 1997; Relatos de El Viejo Antonio. San Cristóbal de Las Casas, CIACH (Centro de Información y Análisis de Chiapas), 1998; Don Durito de la Lacandonia. San Cristóbal de Las Casas, CIACH, 1999. 
bre los mitos de la identidad del mexicano, La jaula de la melancolía (1987), al estilo de las Mitologías (1957) de Roland Barthes ${ }^{43}$.

En conjunto, esta abundancia es suficiente para pensar en la formación paulatina de un nuevo canon de lectura.

\section{LA MINIFICCIÓN Y SU LECTURA}

Tal vez el auge reciente de las formas de escritura itinerante propias del cuento brevísimo, y en particular las del cuento ultracorto, son una consecuencia de nuestra falta de espacio y de tiempo en la vida cotidiana contemporánea, en comparación con otros periodos históricos. Y seguramente también este auge tiene alguna relación con la paulatina difusión de las nuevas formas de la escritura, propiciadas por el empleo de las computadoras.

La última palabra, necesariamente breve, la tiene otro escritor, Irving Howe: «Los escritores que hacen cuentos breves tienen que ser especialmente audaces. Lo apuestan todo a un golpe de inventiva» ${ }^{44}$.

Lo que se apuesta, a fin de cuentas, es el placer cómplice de cada lectura, un placer que tal vez se prolongue más allá de ese momento, y que tal vez afecte la identidad del lector. Esa posibilidad, entre otras, provoca que autor y lector compartan la creencia de que vale la pena seguir apostando todo a «un golpe de inventiva» en cada lectura.

${ }^{43}$ Roger Bartra, La jaula de la melancolía. México, Grijalbo, 1987; Roland BARTHES, Mitologías. México, Siglo XXI, 1980 (1957). Traducción de Héctor Schmucler.

${ }^{44}$ Op. cit., supra, n. 3, p. XIII. 


\title{
RESUMEN
}

\section{El cuento ultracorto bajo el microscopio, por Lauro Zavala.}

En este artículo se propone, a partir del estudio de las antologías canónicas, una tipología de la narrativa cuya extensión no excede la frontera de 2.000 palabras. A partir de esta tipología se establecen las características de la ficción ultracorta, cuya extensión no excede las 200 palabras, y que también ha recibido el nombre de minificción. Por último, se establecen algunas estrategias literarias específicas de este género (intertextualidad irónica, metaficción, ambigüedad semántica y humor) y se señalan las principales formas de hibridación, especialmente con el poema en prosa, la viñeta, la crónica y el ensayo.

Palabras clave: Cuento, cuento ultracorto, minificción, géneros literarios.

\begin{abstract}
In this article the author studies the canonical anthologies of short short fiction, and purports a typology of short short stories under 2.000 words. This typology leads to establishing the characteristics of extremely short writings (under 200 words), which has also received the name minifiction. Finally, some specific literary strategies of the latter genre are stated, such as ironic intertextuality, metafiction, semantic ambiguity, and humor; and its main forms of generic hybridization are studied, especially in relation to prose poem, vignette, chronicle, and essay.
\end{abstract}

Key words: Tale, extremely short writings, minifiction, literary genres. 